\title{
VÍCTOR RAYMUNDO LUNA BENAVIDES
}

Correspondencia

Luis Tolmos Regal

956747941

lutor2017@hotmail.com

Recibido: 05/11/2017

Aprobado: 20/11/2017

Citar como:

Tolmos Regal Luis. Victor Raymundo Luna Benavides. Rev méd panacea. 2017; 6 (3): $123-124$

\author{
Luis Tolmos Regal ${ }^{1}$
}

1. Profesor Principal de la Facultad de Medicina Humana de la Universidad Nacional San Luis Gonzaga. Ica, Perú.

\section{Señor Editor:}

El Mártir de la Facultad de Medicina Humana de la Universidad Nacional "San Luis Gonzaga" de Ica, Nació el 25 de Marzo de 1945.

Es trascendente que en los últimos años se venga reconociendo en su verdadera dimensión y reparándose esa inmensa deuda con este insigne personaje de la Facultad colocándolo en el verdadero lugar, el lugar que le corresponde en la Historia, ya que por esa gran lucha emprendida por los estudiantes de medicina con la finalidad de que el Hospital Regional fuese un Hospital Docente, fruto del mismo accidente que sufrió junto a Victoria Astupiña, quedó parapléjico por cuarenta años. Víctor falleció el 11 de Noviembre del 2005 (que terrible tormento) a la edad de 60 años.

Un joven de carácter afable, alegre, risueño, deportista, integrante de la selección de basket-ball de la Facultad que de la noche a la mañana vio frustradas todas sus ilusiones, dedicándose por muchos años al alcohol. Un compañero de él, se convirtió en su fiel amigo, el alumno Otto Chuy Castro (hoy Médico Pediatra) quien debe conocer mucho mejor sus penas, sufrimientos y alegrías. Nunca quiso regresar a la Facultad, pese a las múltiples invitaciones que se le cursaron. En una oportunidad se hizo una colecta en dólares para pagar su estadía en el mejor hotel de la ciudad por esas épocas, el Hotel de Turistas, invitación que igualmente fue rechazada. Por esos tiempos, él ya radicaba en Lima.

En Lima trabajó en la Oficina Central del Banco de Crédito durante varios años a la que iba en su silla de ruedas.

El suscrito siempre manifestó que lo último que quería hacer es erigirle un monumento al igual que el de Victoria, consiguiéndolo sólo a medias ya que el mismo es de yeso y cal, y no de bronce como el de Victoria y como lo hubiese querido, esto se realizó 37 años después de la Gloriosa Gesta, el 19 de Octubre del 2002. Nunca es tarde para reparar una inmensa injusticia.

Se creó la alameda Víctor Luna Benavides con la finalidad de tener vivo su ejemplo y recordarlo permanentemente. Para esto es justo recordar que se contó con la valiosa colaboración de la profesora Lic. Gladys Gallardo y los estudiantes de la época en la construcción de bancas ornamentales que felizmente subsisten hasta hoy, el sembrado de plantas, etc. Hay un gran rótulo que señala esta alameda, el cual se encuentra despintado por acción del sol. El suscrito se encarga del cuidado del modesto monumento que no es de bronce como ya se mencionó, de que el piso esté encerado y las plantas podadas y bien presentadas.

En el año 2013 con motivo de las Bodas de Oro se construyó la Tercera Gruta a María Auxiliadora Patrona de la Facultad de Medicina al costado del Busto de Víctor ¡Que mejor regalo! ¡Qué mejor compañía para nuestro mártir, que tener por compañía a Nuestra Madre!

VITÍN LA FACULTAD Y LA COMUNIDAD DE ICA AÚN ESTÁN EN DEUDA CONTIGO! 


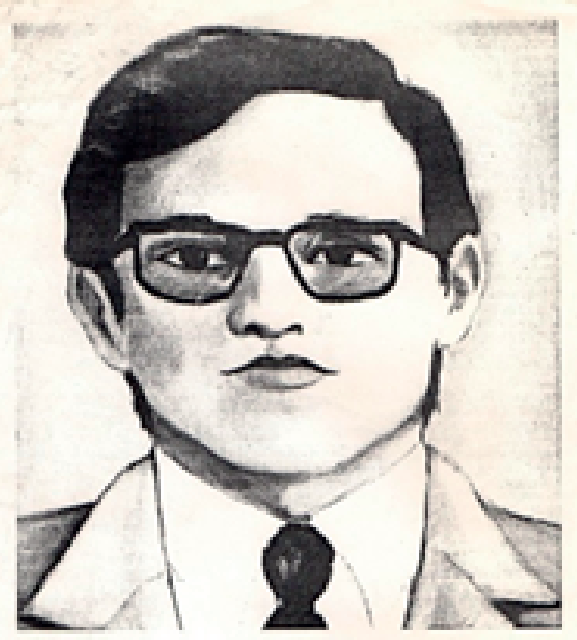

VICTOR LUNA BENAVIDES

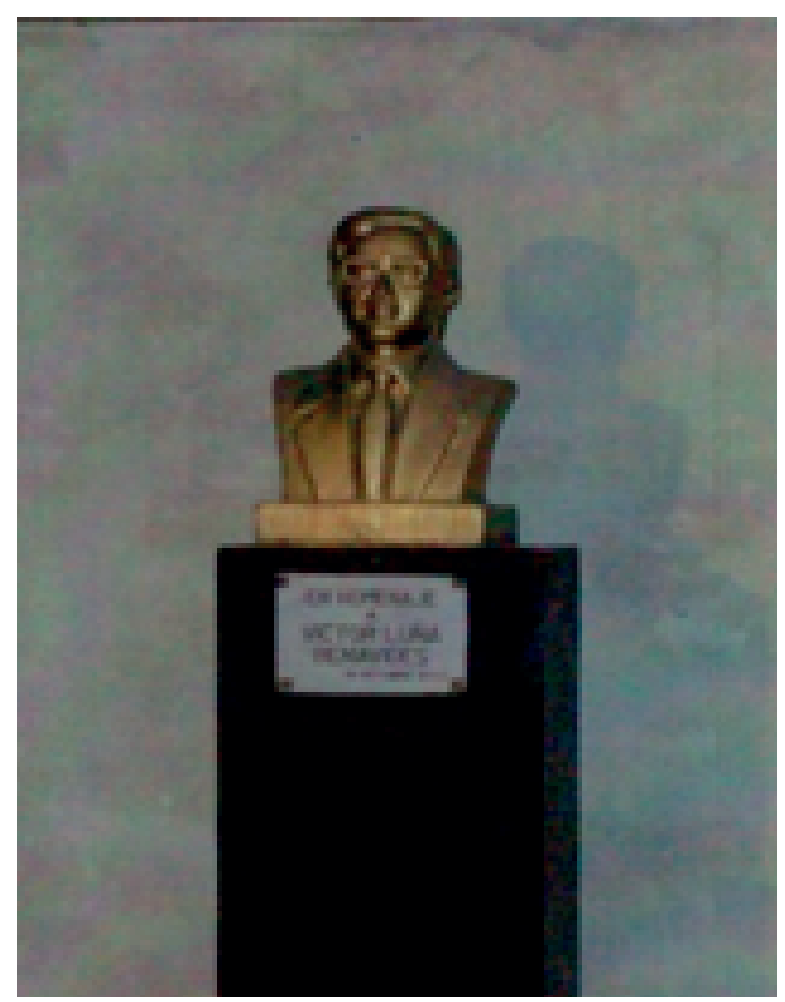

Figura 2. Busto de Víctor Luna Benavides 1945- 2005

Las ediciones anteriores de revista médica PANACEA están disponibles en:

\section{www.revpanacea.unica.edu.pe}

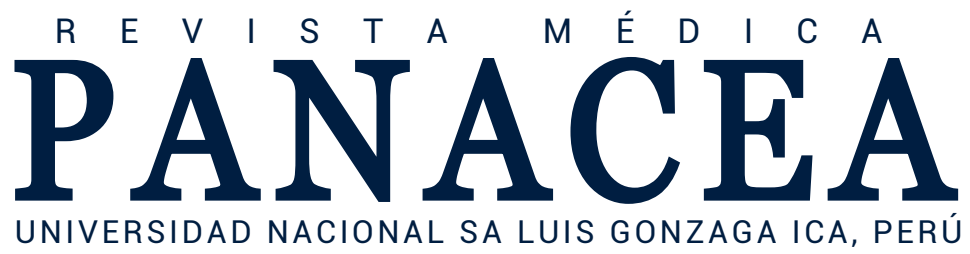

